\title{
Differential Effect of Fatty Acids in Nervous Control of Energy Balance
}

\author{
Christophe Magnan, Hervé Le Stunff and Stéphanie Migrenne \\ Université Paris Diderot, Sorbonne Paris Cité, Biologie Fonctionnelle et Adaptative, \\ Equipe d'accueil conventionnée Centre National de la Recherche Scientifique, Paris,
}

France

\section{Introduction}

Energy homeostasis is kept through a complex interplay of nutritional, neuronal and hormonal inputs that are integrated at the level of the central nervous system (CNS). A disruption of this regulation gives rise to life-threatening conditions that include obesity and type-2 diabetes, pathologies that are strongly linked epidemiologically and experimentally. The hypothalamus is a key integrator of nutrient-induced signals of hunger and satiety, crucial for processing information regarding energy stores and food availability. Much effort has been focused on the identification of hypothalamic pathways that control food intake but, until now, little attention has been given to a potential role for the hypothalamus in direct control of glucose homeostasis and nergy balance. Recent studies have cast a new light on the role of the CNS in regulating peripheral glucose via a hypothalamic fatty acid (FA)-sensing device that detects nutrient availability and relays, through the autonomic nervous system, a negative feedback signal on food intake, insulin sensitivity and insulin secretion. Indeed, accumulating evidences suggest that FA are used in specific areas of CNS not as nutrients, but as cellular messengers which inform "FA sensitive neurons" about the energy status of the whole body (Blouet \& Schwartz, 2010; Migrenne et al., 2006; Migrenne et al., 2011). Thus it has been described that up to $70 \%$ of hypothalamic arcuate nucleus (ARC) and ventromedian nucleus (VMN) neurons are either excited or inhibited by long chain fatty acids such as oleic acid (Jo et al., 2009; Le Foll et al., 2009; Migrenne et al., 2011). Within the VMN, $90 \%$ of the glucosensing neurons also have their activity altered by FA. In a large percentage of these neurons, glucose and FA have opposing effects on neuronal activity, much as they do on intracellular metabolism in many other cells (Randle et al., 1994). Neuronal FA sensing mechanisms include activation of the $K_{\text {ATP }}$ channel by long chain fatty acid acyl CoA (Gribble et al., 1998) or inactivation by generation of ATP or reactive oxygen species during mitochondrial $\beta$-oxidation (Jo et al., 2009; Le Foll et al., 2009; Migrenne et al., 2011; Wang et al., 2006). Many fatty acid sensing neurons are activated by interaction of long chain fatty acids with the fatty acid transporter/receptor, FAT/CD36, presumably by activation of store-operated calcium channels by a mechanism that is independent of fatty acid metabolism (Jo et al., 2009). Importantly, most neurons utilize FA primarily for membrane production rather than as a metabolic substrate (Rapoport et al., 2001; Smith \& Nagura, 2001) and only nanomolar concentrations of fatty acid are required to 
alter the activity of fatty acid sensing neurons in the absence of astrocytes (Jo et al., 2009). While cerebral lipids are both produced in the brain and transported into it from the periphery (Rapoport et al., 2001; Smith \& Nagura, 2001), the mechanism of this transport and the actual levels of various FA in the extracellular space in the brain remains largely unknown. As mentioned above, hypothalamic FA sensing may be involved in the control of feeding behaviour, hepatic glucose production and insulin secretion. It seems also that intracellular FA metabolism is important to relay their effects ( $\beta$ oxidation has been showed to be involved in oleate effect in hypothalamus) (Cruciani-Guglielmacci et al., 2004; Obici et al., 2003). In addition differential effect of FA in regard to feeding behaviour or glucose production may be related to their chain length and degree of saturation. For exemple, it has been showed in rodents that oleate both inhibits food intake and hepatic glucose production whereas octanoate has no effect on these parameters (Obici et al., 2002). In another study we showed that intracerebroventricular infusion of palmitate induced an hepatic insulin resistance and an impaired insulin signaling in hypothalamus (Benoit et al., 2009). In contrast oleate has no deleterious effect in this parameter (Benoit et al., 2009). Poly-unsaturated fatty acids (PUFA) such as n-3 or n-6 may have also different effects in neuronal activity and cognitive function such as memorization. The present work was aimed at studying differential effect of FA or triglycerides emulsion infused in rats in glucose homeostasis. In addition, in order to identify molecular mechanisms involved in specific effects of FA, mRNA expression of key genes involved in FA metabolism as well as ceramides and diacylglycerol (DAG) content have been measured in hypothalamus. Regarding physiopathology aspects it must be pointed out that dysfunction of central FA sensing could be a contributing factor to the early development of type 2 diabetes mellitus and/or obesity which leads to further dysfunction in predisposed subjects. A better understanding of these mechanisms, as well as further characterization of FA sensitive neurons and their role in physiological and pathological processes, might lead to identification of novel pharmacological targets for the prevention and treatment of diabetes and obesity.

\section{FA sensing in hypothalamus}

There is now growing amount of evidence suggesting, at least in rodents models, that some neurons located in hypothalamus (and brainstem) are sensitive to FA, ie their electrical activity is either increased or decreased in presence of variations of FA concentration. This has been evidenced both in vivo and in vitro. A key point is the transport of FA across the blood brain barrier (BBB). It cannot be excluded that FA may be produce directly in neurons from hydrolysis of intracellular troglycerides (TG).

\subsection{Transport of FA uptake into the brain and neurons}

Cerebral lipids are an essential component of both membranes and intracellular signalling pathways. They represent $50 \%$ of brain dry weight; the highest organ lipid content after adipose tissue (Edmond, 2001; Watkins et al., 2001). However, the mechanism by which FA are transported into the brain remains poorly understood. A growing body of evidence suggests that cerebral lipids are derived both from local synthesis and uptake from the blood (Rapoport et al., 2001). Several studies show that some poly-unsaturated FA (PUFA) have the ability to cross the BBB (Rapoport et al., 2001; Smith \& Nagura, 2001). The question 
of whether brain FA uptake occurs by passive diffusion or involves a protein which facilitates the transport is still matter of debate. However, once across the BBB, it is likely that neurons can take up FA since some neurons do appear to have FA transporters. For example, dissociated neurons from the VMN of rats express mRNA's for FA transport proteins (FATP)-1 and 4 and the FA transporter/receptor FAT/CD36 (Le Foll et al., 2009). Also, while it is unlikely that neurons derive much of their energy supply from FA, these same neurons do express mRNA's for the intracellular metabolism of FA such as long chain acyl-CoA synthetase, carnitine palmitoyltransferase-1a and 1c and uncoupling protein-2 (Le Foll et al., 2009). They also express enzymes for de novo FA synthesis such as FA synthetase (Le Foll et al., 2009). But, it seems likely that much of the reported oxidation of FA such as palmitate in the brain probably occurs in astrocytes (Escartin et al., 2007) whereas other FA such as arachidonate are largely incorporated into phospholipids (Rapoport et al., 2001).

\subsection{Some hypothalamic neurons are lipid responsive}

The presence of neurons sensitive to variations in extracellular glucose levels is clearly demonstrated in the brain (Gilbert et al., 2003) and in particular in the hypothalamus (review in (Luquet \& Magnan, 2009; Migrenne et al., 2011; Penicaud et al., 2002). Thirty-five years ago Oomura and colleagues first showed that FA activated lateral hypothalamic neurons which suggested a role for FA as neuronal signaling molecules (Oomura et al., 1975). As shown in Figure 1, FA also modify neuronal firing rate in hypothalamic arcuate nucleus (ARC) (Wang et al., 2006). Both FA "excited" (around 20\% of arcuate neurons) and "inhibited" neurons (about 12\%) are detected in arcuate nucleus of rat using this patch clamp technique (Wang et al., 2006). These FA sensitive neurons are also detected in vivo using multi-unit recording approaches (Wang et al., 2006). Therefore we demonstrated that single injection of oleic acid (OA) through carotid artery induced either increased or decreased neuronal activity depending on location of microelectrode in hypothalamus. It seems that some areas are mainly composed with FA "excited" neurons whereas others are mainly composed with FA "inhibited" neurons. Such data also suggest that physiological variations of plasma FA concentrations (reflecting the metabolic state and energy availability) can be detected and integrated by FA sensing neurons in critical brain areas involved in the regulation of feeding behaviour, glucose and lipid metabolism (Clement et al., 2002; Obici et al., 2002). Indeed increased plasma FA concentration during fasted or starvation may be detected by FA excited neurons which in turn may have an impact on nervous control of energy balance. On the contrary decreased plasma FA concentration during a meal could be also detected by these sensitive neurons which may act a satiety signal like insulin and glucose do during a meal when acting on hypothalamus sensitive neurons (Gilbert et al., 2003).

The physiological relevance of brain FA sensing is supported by various studies showing that local increases in brain and hypothalamic FA levels are associated with changes in insulin secretion and hepatic glucose output with variable effects on food intake (Clement et al., 2002; Obici et al., 2002; Ross et al., 2010; Schwinkendorf et al., 2010). For example, a 6 hour intracerebroventricular (icv) infusion of the monounsaturated FA, oleic acid (OA), reduced food intake as well as hepatic glucose production (HGP) (Obici et al., 2002). Reducing hypothalamic FA oxidation by inhibition of carnitine palmitoyl transferase -1 (CPT1), the enzyme that promotes $\beta$-oxidation by facilitating transport of medium- and 
long-chain FA into mitochondria, mimicked these effects on food intake and HGP induced by icv infusion of OA (Obici et al., 2003). In another study a direct bilateral infusion of OA into the mediobasal hypothalamus decreased hepatic glucose production (Ross et al., 2010). In addition, it seems that the hypothalamus differentially senses FA. For example, icv infusions of OA or docosahexanoic acid, but not palmitic acid, reduce food intake and body weight (Schwinkendorf et al., 2010). However, icv and direct infusions of FA into the brain are not physiological. Thus, they might produce non-specific effects by evoking an inflammatory response by irritating ependymocytes and tanycytes lining the ventricles or by exciting microglia and astrocytes in the brain parenchyma.

A

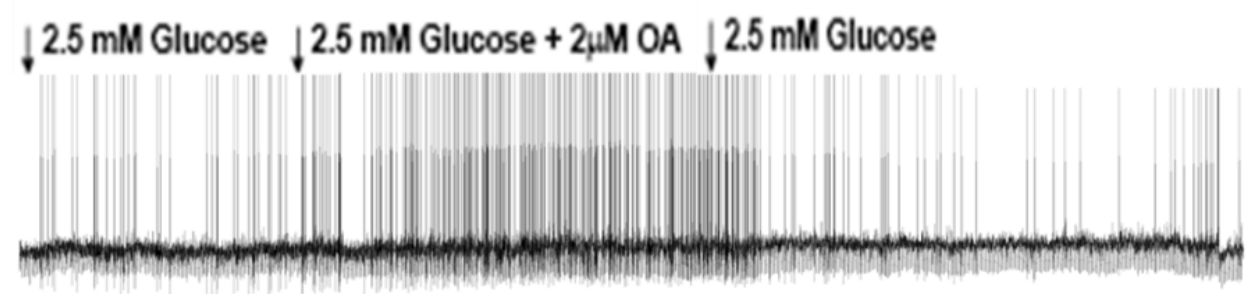

B

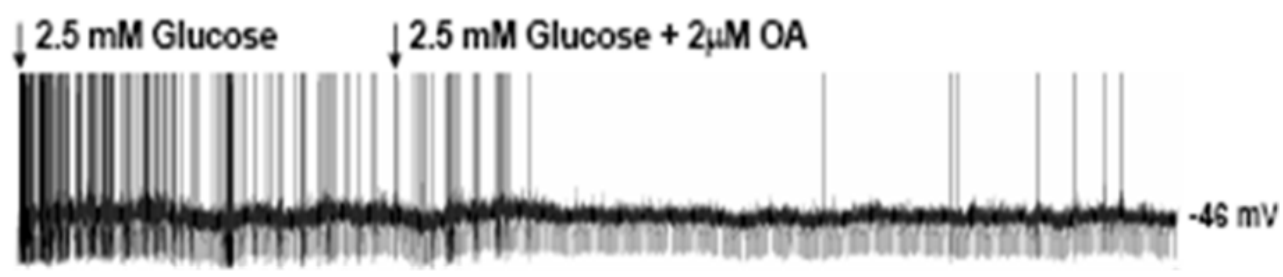

C

\section{$2.5 \mathrm{mM}$ Glucose $+2 \mu \mathrm{M} \mathrm{OA}+100 \mu \mathrm{M}$ Tolbutamide}

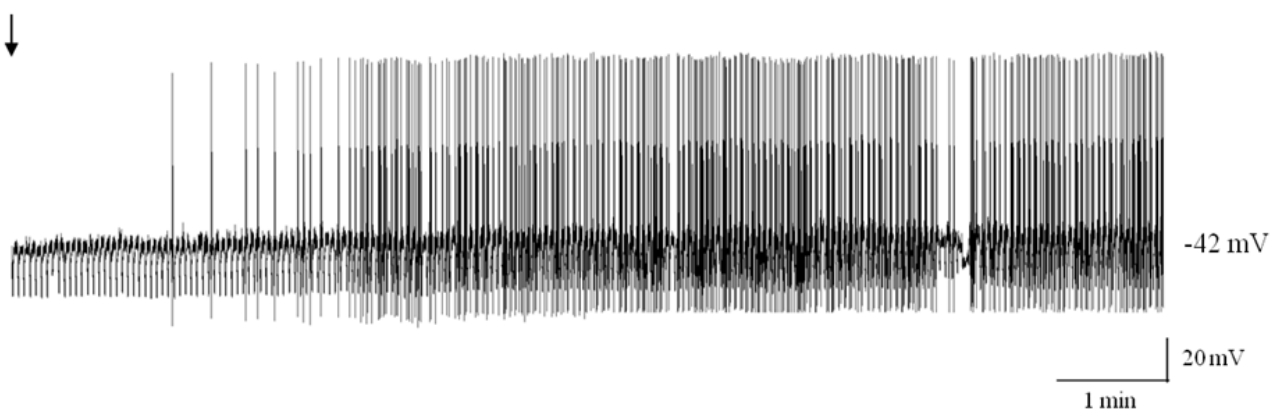

Fig. 1. Fragments of whole cell current clamp recordings of oleic acid (OA) excited (A) and inhibited (B) neuron in arcuate nucleus of rat (Adapted from Wang et al, 2006 et Migrenne et al, 2006). The inhibitory effect of OA on neuronal activity is inhibited by tolbutamide (C), suggesting involvement of $\mathrm{K}_{\mathrm{ATP}}$ channels in OA effect. 
More physiological routes include elevating systemic levels of FA or infusing them directly into the carotid arteries, the major route by which FA reach the forebrain. For example, a twofold increase in plasma triglycerides produced by a two day systemic infusion of triglycerides was associated with decreased sympathetic activity. This reduced sympathetic tone, which is also produced by central FA infusions (Magnan et al., 1999), might contribute to the associated FA-induced exaggeration of glucose-induced insulin secretion (GIIS), a condition which is similar to what occurs in the prediabetic state (Magnan et al., 1999). Also, this exaggerated GIIS and a reduction in HGP were mimicked by infusing triglycerides into the carotid artery (Cruciani-Guglielmacci et al., 2004). These exaggerated responses were reduced by central inhibition CPT1 (Magnan et al., 1999). Similarly, central CPT1 inhibition was associated with an increase in the acyl CoA intracellular pool which was postulated to be the "final" satiety signal rather than FA themselves (review in (Lam et al., 2005; Luquet \& Magnan, 2009).

However, there are at least two potential problems involved in the interpretation of such in vivo data. First, the idea that increases in brain FA levels act as a satiety signal to inhibit feeding (Obici et al., 2003) is counterintuitive given the fact that plasma FA levels do not rise substantially after food ingestion, but do rise significantly during fasting (Ruge et al., 2009). Second, the vast majority of FA oxidation in the brain occurs in astrocytes rather than neurons (Escartin et al., 2007). While a select group of neurons in the hypothalamus clearly responds directly to changes in ambient FA levels by altering their activity (Le Foll et al., 2009; Oomura et al., 1975), only a relatively small percentage of these responses depend upon neuronal FA metabolism (Le Foll et al., 2009). Furthermore, although $\beta$-oxidation and formation of malonylCoA and FA metabolites such as acyl-CoA may be mediators of the in vivo effects produced by FA infusions (Dowell et al., 2005; Migrenne et al., 2011) it is likely that most of these occur at the level of the astrocyte. If so, then there must be a mechanism by which alterations in astrocyte FA metabolism can provide a signal to those neurons which regulate HGP and food intake. We suggest that this communication between astrocyte FA metabolism and neuronal FA sensing involves the production and export of ketone bodies from astrocytes (Escartin et al., 2007) and subsequent uptake by neurons. Finally another important issue is the nature of the FA and its effect on sensitive neurons. As previously mentioned OA and octanoate have differential effect regarding food intake or hepatic glucose production, suggesting that medium or long chain fatty acids may have different effects (Obici et al., 2002). Thus, the aim of the present study was to test whether different FA may have different effect on glucose homeostasis when infused in rats brains through carotid artery. Triglyceride emulsion either enriched in $\omega 3, \omega 6$ FA or saturated FA (lard oil) have been also tested.

\section{Methods}

All animal care and experimental procedures were approved by the animal ethics committee of the university Paris-Diderot. Four weeks-old male wistar rats were purchased from Charles Rivers (Lyon, France) and housed at $21^{\circ} \mathrm{C}$ with normal light/dark cycle and free access to water and food.

\subsection{First serie of experiments}

Rats received an intracerebroventricular (icv) infusion of FA during 3 days. Briefly, rats anesthetized with isoflurane were stereotactically implanted with a chronic stainless steel 
cannula in the right lateral cerebral ventricle. The cannula was connected via a polyethylene catheter to a subcutaneously osmotic minipump filled up with FA (oleate, octanoate or linolenate) or saline. Infusions started $6 \mathrm{~h}$ after surgery. The rate of infusion was $0.5 \mu \mathrm{l} / \mathrm{h}$. Blood was daily removed $(\sim 80 \mu \mathrm{l})$ from caudal vessels for measurement of plasma substrate (FA and glucose) and insulin. Food intake was daily measured. At day 3 of infusion glucose-induced insulin secretion (GIIS) was measured in response to a single intraperitoneal injection of glucose $(0.5 \mathrm{~g} / \mathrm{kg} \mathrm{bw})$. was made in overnight fasted rats. The glycemia was determined by a glucometer (AccuChek, Rabalot, France) from $2 \mu \mathrm{l}$ collected from the tip of the tail vein at time $0,5,10,15,20,30$ and $60 \mathrm{~min}$. In addition 20 $\mu \mathrm{l}$ of blood was sampled at the same time for insulin measurement (RIA, Diasorin, France). In another serie of experiments, etomoxir (CPT1 inhibitor) was concomitantly infused with FA. At the end of experiment brain were removed and five hypothalamus nuclei (arcuate, lateral, ventromedian, paraventricular and dorsomedian) were micropunched in order to measure gene expression (acetylCoA carboxylase, ACC, carnitine palmitoyl transferase, CPT1, FA synthase, FAS, G protein related peptide GPR41). Briefly, total RNA was isolated from the hypothalamus using RNeasy Lipid kit (Qiagen). To remove residual DNA contamination, the RNA samples were treated with DNAse RNAse-free (Qiagen). $4 \mu \mathrm{g}$ of total RNA from each sample was reverse transcribed with $40 \mathrm{U}$ of M-MLV Reverse Transcriptase (Invitrogen, life technologies) using random hexamer primers.

\subsection{Second serie of experiments}

In a second serie of experiments our goal was to test the effect of different triglyceride emulsion on glucose tolerance and both diacylglycerol and ceramides content in hypothalamus. To that end rats received an intracarotid infusion during $24 \mathrm{~h}$ of lard oil, mainly composed of saturated FA (SFA), $\omega 3$-enriched (Omegaven, Santec, France) or $\omega 6-$ enriched (Ivelip, Rabalot, France) polyunsaturated FA (PUFA) triglyceride emulsion. The long-term unrestrained infusion technique was used, as previously described (Gilbert et al., 2003). Briefly, 5 days before the beginning of the infusion, rats were anaesthetized with isoflurane for catheterization of right carotid artery, towards the brain. Catheter was then exteriorized at the vertex of the head, and animals were allowed to recover for 5 days. For infusion, catheter is connected to a swiveling infusion device, allowing the animal free access to water and food and infused with a triglyceride emulsion. Food intake was measured after the $24 \mathrm{~h}$ infusion period. In another set of experiments, oral glucose tolerance test $(3 \mathrm{~g} / \mathrm{kg}$, OGTT) was also performed.

\subsection{Extraction and analysis of ceramids and DAG content in the hypothalamus}

Diacylglycerol and ceramide levels in tissues extracts were measured by the diacylglycerol kinase enzymatic method as previously described (Escalante-Alcalde et al., 2003; Le Stunff et al., 2002). Briefly, aliquots of the chloroform phases from cellular lipid extracts were resuspended in $7.5 \%(\mathrm{w} / \mathrm{v})$ octyl- $\beta$-D-glucopyranoside/5 $\mathrm{mM}$ cardiolipin in $1 \mathrm{mM}$ DETPAC/10 mM imidazole ( $\mathrm{pH}$ 6.6). The enzymatic reaction was started by the addition of $20 \mathrm{mM}$ DTT, $0.88 \mathrm{U} / \mathrm{ml}$ E. coli diacylglycerol kinase, $5 \mu \mathrm{Ci} / 10 \mathrm{mM}[\gamma-32 \mathrm{P}] \mathrm{ATP}$ and the reaction buffer (100 mM imidazole ( $\mathrm{pH}$ 6.6), $100 \mathrm{mM} \mathrm{NaCl}, 25 \mathrm{mM} \mathrm{MgCl} 2$, and $2 \mathrm{mM}$ EGTA). After incubation for $1 \mathrm{~h}$ at room temperature, lipids were extracted with 
chloroform/methanol/HCl (100:100:1, v/v) and $1 \mathrm{M} \mathrm{KCl}$. [ $\gamma$-32P]-phosphatidic acid was resolved by TLC with chloroform/acetone/methanol/acetic acid/water (10:4:3:2:1, v/v) and quantified with a Molecular Dynamics Storm PhosphorImager. Known amounts of diacylgycerol and ceramide standards were included with each assay. Ceramide and diacylglycerol levels were expressed as pmol by nmol of phospholipid (PL) levels. Total phospholipids present in cellular lipid extracts used for ceramide analysis were quantified as described previously (Escalante-Alcalde et al., 2003; Le Stunff et al., 2002) with minor modifications. Briefly, a mixture of $10 \mathrm{~N} \mathrm{H}_{2} \mathrm{SO}_{4} / 70 \%$ perchloric acid $(3: 1, \mathrm{v} / \mathrm{v})$ was added to lipid extracts which were incubated for $30 \mathrm{~min}$ at $210^{\circ} \mathrm{C}$. After cooling, water and $4.2 \%$ ammonium molybdate in $4 \mathrm{~N} \mathrm{HCl} / 0.045 \%$ malachite green $(1: 3 \mathrm{v} / \mathrm{v})$ was added. Samples were incubated at $37^{\circ} \mathrm{C}$ for $30 \mathrm{~min}$, and absorbance was measured at $660 \mathrm{~nm}$.

\section{Results}

In the first serie of experiment, whatever the FA ie oleate or linolenate), there was no change in food intake during experiment (data not shown). Basal plasma glucose, FA, and insulin concentrations were also similar in all groups. As displayed in figure 2, in response to glucose load in linoleate group time course of glycemia was similar to control but was associated with an increased glucose induced insulin secretion (GIIS), suggesting an insulin resistance state which was compensated by this increased GIIS. In oleate infused group there was no change in plasma glucose or GIIS compared to controls.

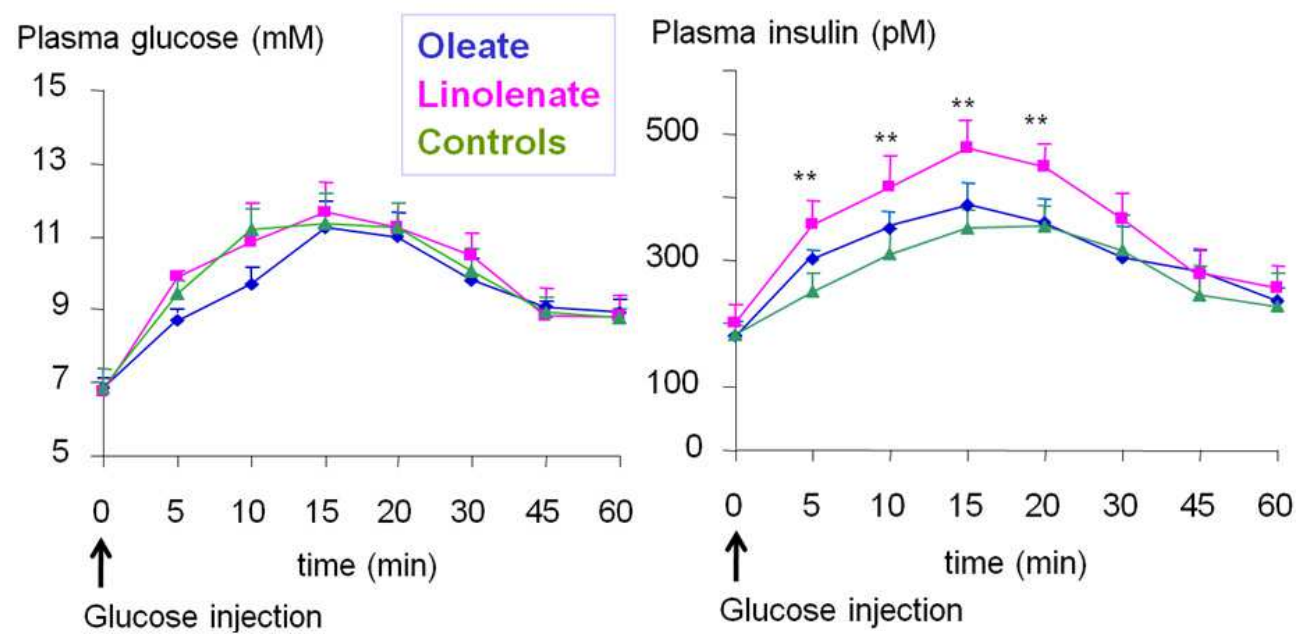

Fig. 2. Time course of plasma glucose and insulin concentration in response to glucose injection in oleate, linolenate, and $\mathrm{NaCl}$ (controls) icv $24 \mathrm{~h}$ infused rats. ${ }^{* *}, \mathrm{p}<0.01$ vs oleate and controls.

In order to test whether $\beta$ oxidation was required to relay FA effect, GIIS was measured in presence or not of etomoxir a specifix inhibitor of CPT1 activity, a rate-limiting enzyme of $\beta$ oxidation (figure 3). Results are expressed as insulinogenic index (ie ratio of areas under the curve of insulin to glucose during GIIS). Effect of linolenate on GIIS was reversed by etomoxir. 


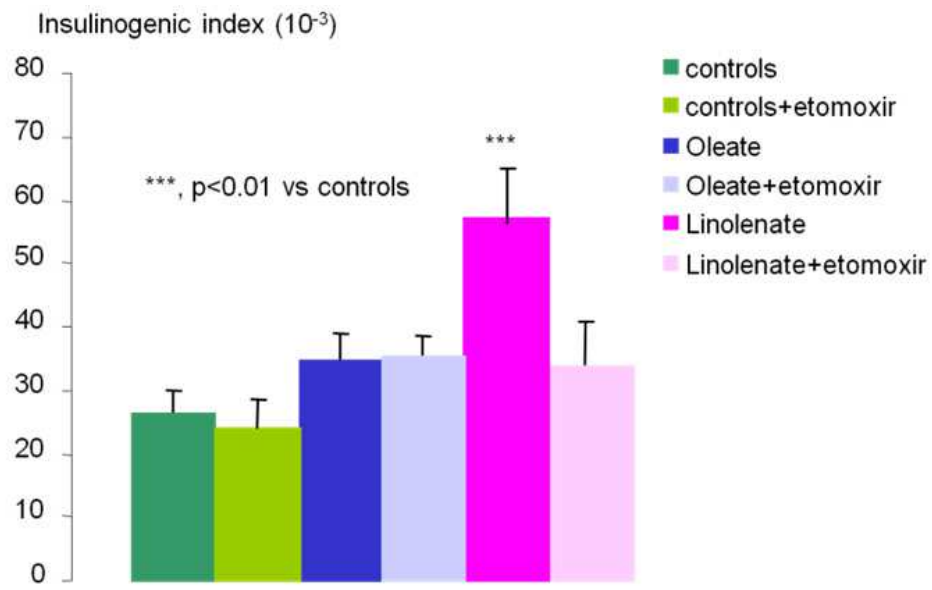

Fig. 3. Insulinogenic index in control rats, oleate and linolenate infused rats with or without etomoxir, a specific inhibitor of CPT1. ${ }^{* *} \mathrm{p}<0.01$ vs controls

Hypothalamic gene expression have been measured in five areas (figure 4) involved in nervous control of energy balance: arcuate nucleus (ARC), ventromedian (VMH), lateral $(\mathrm{LH})$, dorsomedian hypothalamus $(\mathrm{DMH})$ and paraventricular nucleus (PVN). Studied genes were CPT1 (carnitine palmitoyl transferase 1), FAS (fatty acid synthase), GPR41 (G protein related receptor 41, GPR40 and 43 have been also tested but were not detected in our models), ACC $\beta$ (Acetyl carboxylase $\beta$ ) and AMPKa2. Results are displayed in figure 5.

ARC: Arcuate nucleus VMH: Ventromedian hypothalamus LH: Lateral hypothalamus

DMH: Dorsomedian hypothalamus

PVN: Paraventricular nucleus

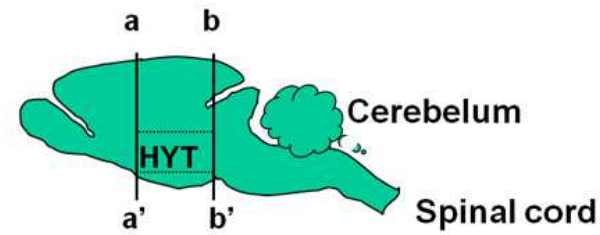

b

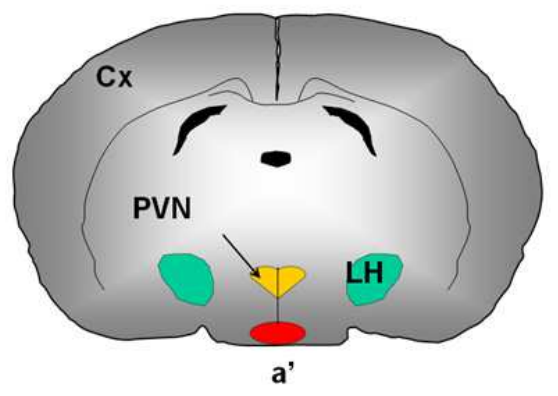

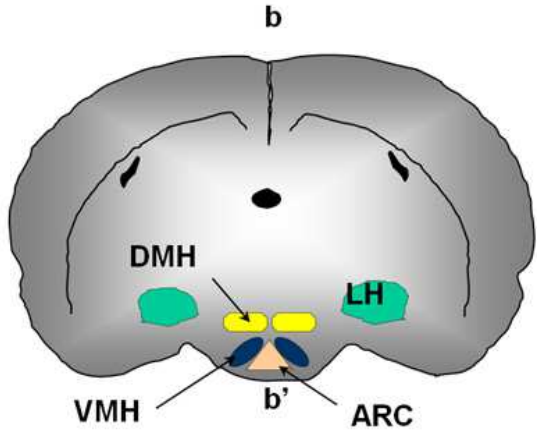

Fig. 4. Map of hypothalamic areas involved in nervous control of energy homeostasis. Arcuate nucleus (ARC), ventromedian (VMH), lateral (LH), dorsomedian hypothalamus $(\mathrm{DMH})$ and paraventricular nucleus $(\mathrm{PVN})$. 
Hypothalamic gene expression were also modified in some areas depending on FA (figure 5). For example, FAS expression was inhibited in all nuclei except in VMH of linolenate infused rats. GPR41 was up-regulated in ARC of linolenate infused rats.

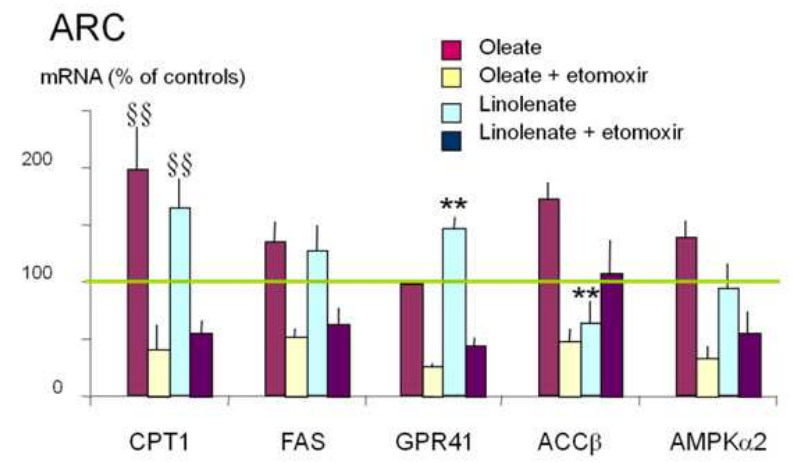

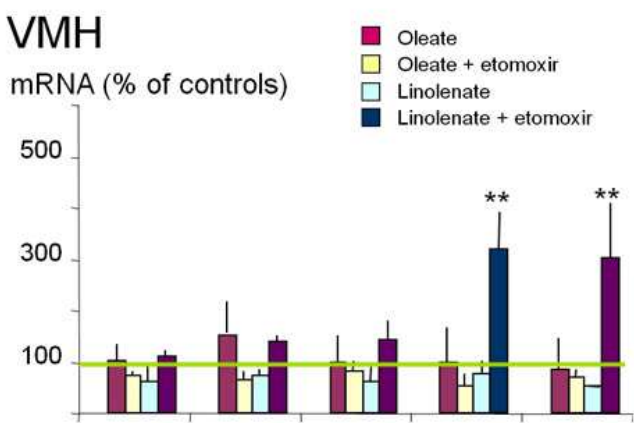

CPT1 FAS GPR41 ACC $\beta$ AMPK $\alpha 2$

\section{$\mathrm{LH}$ \\ mRNA (\% of controls)}

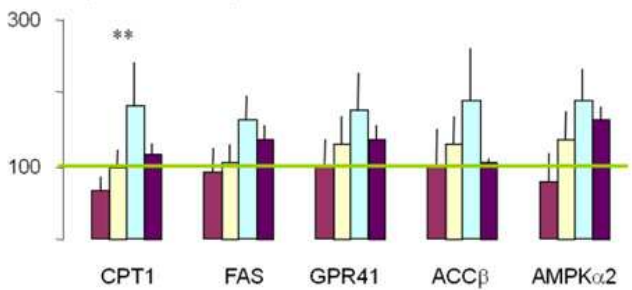

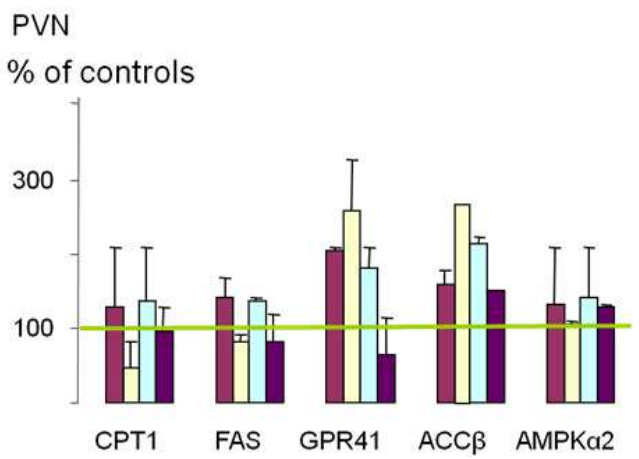

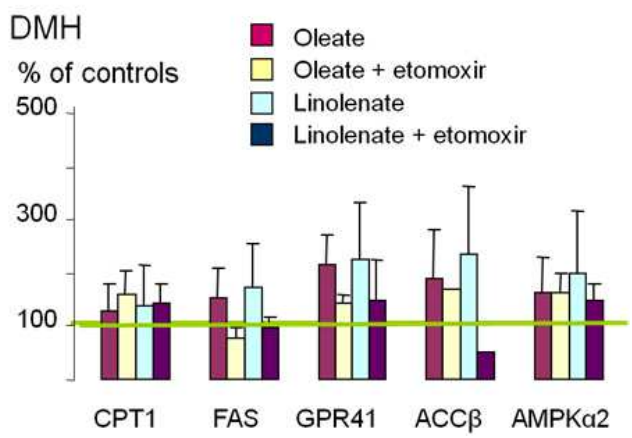

Fig. 5. mRNA expressionof target gene in different hypothalamic areas in oleate or linolenate $+/$ - etomoxir. The green line represents gene expression in control rats (infused with $\mathrm{NaCl}$ ). ${ }^{* *}, \mathrm{p}<0.01$ vs controls. $\$ \S, \mathrm{p}<0.01$ vs controls. ARC: arcuate nucleus; VMH: ventromedian hypothalamus; LH: lateral hypothalamus; DMH: dorsomedian hypothalamus; PVN: paraventricular nucleus. 
In the second serie of experiments, we first measured food intake (figure 6). As depicted, there was a decreased in food intake with omegaven and ivelip infusion but not with lard oil.

口Controls

口Omegaven

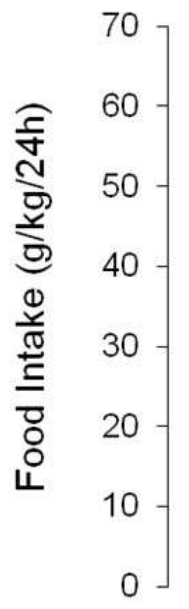

ㅁvelip

Lard oil
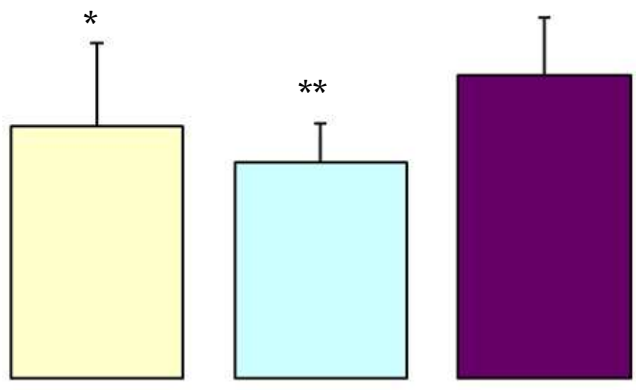

Fig. 6. Measurement of food intake. ${ }^{*}, \mathrm{p}<0.05$ vs controls, ${ }^{* *} \mathrm{p}<0.01$ vs controls.

Figure 7 depicted time course and area under the curse of glycemia in response to oral glucose tolerance test. Lard oil induced glucose intolerance compared to controls.

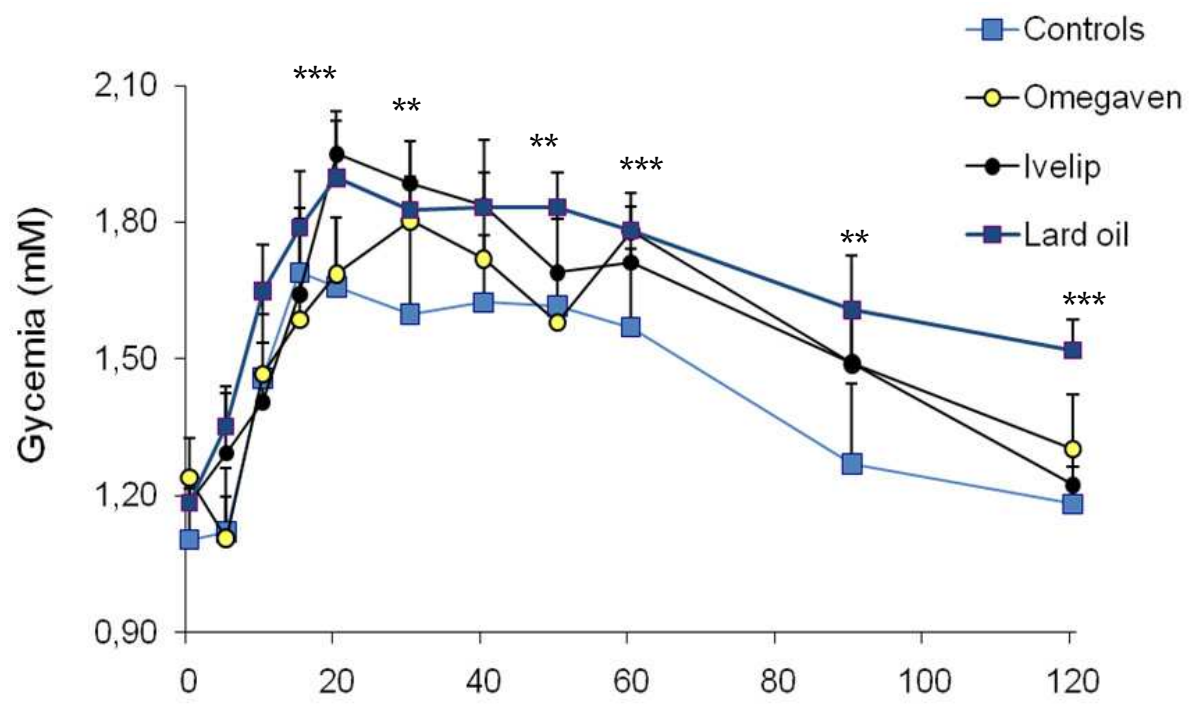


口Controls
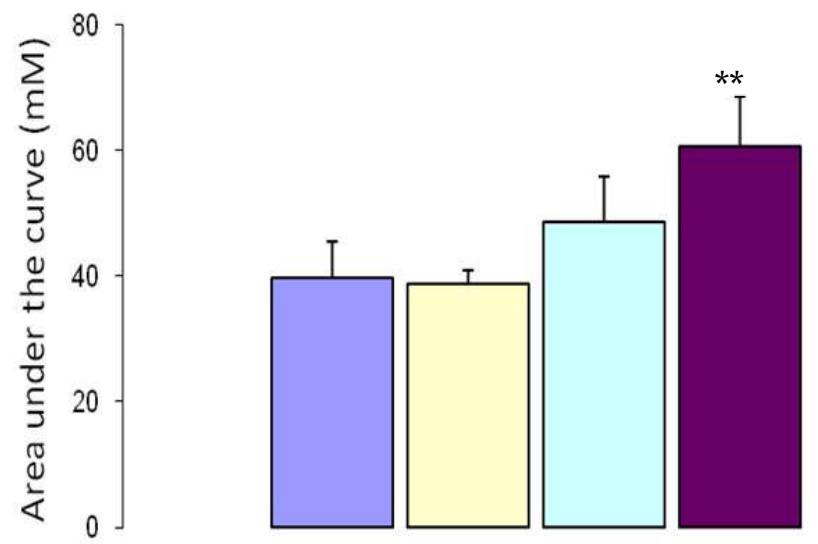

口Omegaven

口lvelip

- Lard oil

Fig. 7. Time course of glycemia (left) and area under the curve of glycemia during oral glucose tolerance test (right). ${ }^{* *} \mathrm{p}<0.01,{ }^{* * *} \mathrm{p}<0.001$ vs controls.

Interestingly, the effect of lard oil was associated with an accumulation of ceramide in the hypothalamus (figure 8). Therefore, our data suggest that ceramide accumulation in the hypothalamus following icv infusion of saturated fatty acid could contribute to the installation of an insulin resistant state by altering nervous output and consequently nervous control of insulin secretion and action.

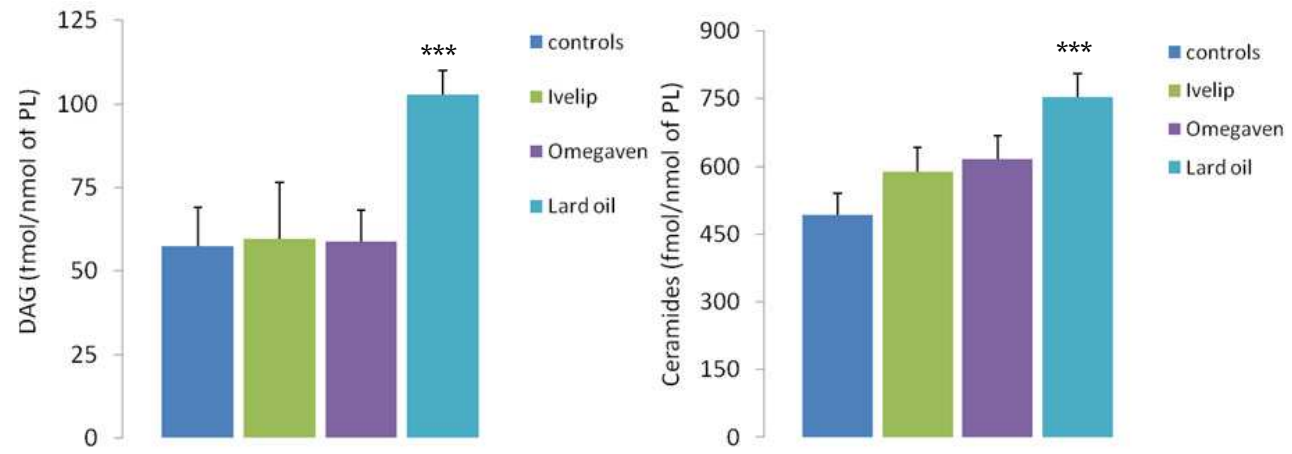

Fig. 8. Hypothalamic content of diacylglycerol (DAG) and ceramides in rats infused through carotid artery with $\mathrm{NaCl}$ (controls), Ivelip, Omegaven or Lard oil during $24 \mathrm{~h} .{ }^{* * *} \mathrm{p}<0.001$ vs controls.

\section{Discussion}

It is now clearly evidenced that hypothalamic FA sensing is an important regulator of nervous control of energy balance. In the present study we highlighted the differential 
effects of FA regarding their chain length and degree of saturation. We firstly evidenced here that oleate and linolenate have differential effects in regard to glucose homeostasis and GIIS. Especially linolenate induced increased GIIS compared to both oleate and control group whereas time course of glycemia remained similar. Thus there is a difference between effect of monounsaturated and polyunsaturated fatty acids when infused toward the brain. This suggest activation of different pathways. It must be pointed out that we previously demonstrated that short term infusion of oleate (6h and $24 \mathrm{~h}$ ) induced an increased in insulin secretion induced by glucose compared to control rats (Migrenne et al., 2006; Wang et al., 2006). In the present study infusion was made during 3 days which can explain different effect in short vs long term infusion peridod. Indeed we cannot exclude an adaptation to oleate effect when infusion stay longer. In the same way of ideas, inhibitory effect of central infusion of oleate on food intake was also lost after 3 days of infusion as previously evidenced by obici et al (Obici et al., 2002). In contrast, in the present study effect of linolenate was still present after 3 days of infusion. Linolenate effect may induce an insulinresistance state and increased GIIS could be an adaptation to this insulin resistance state. By acting on FA sensitive neurons, linolenate may affect nervous output from CNS, especially autonomic nervous system. This change in autonomic nervous system balance will in turn modify nervous control of insulin secretion and action. We previously demonstrated that lipid infusion induced changes in both sympathetic and parasympathetic nervous activity in both rodents (Magnan et al., 1999) and humans (Magnan et al., 2001). In both studies decreased sympathetic nervous activity induced an increased insulin secretion in response to glucose and insulin resistance. In addition, in the present study we showed that linolenate effect involved its metabolism since it had no more effect in presence of etomoxir an inhibitor of $\beta$ oxidation. The involvement of $\beta$ oxidation to relay FA effect on sensitive neurons have been also described in different models by us (Cruciani-Guglielmacci et al., 2004) and others (Obici et al., 2003). Finally that specific effects of linolenate compared to oleate could be, at least in part, related to differential gene transcription involved in FA metabolism such as CPT1, FAS or ACC in key areas of hypothalamus. More precisely in ARC and LH CPT1 expression was increased in linolenate infused rats and etomoxir induced a decreased in this gene and its return to basal value. However, it is difficult to further analyze these results since in other nuclei, there is no change of CPT1 expression. In addition, in some area others genes are differently expressed such as AMPKa2 or ACC $\beta$, both key enzymes of glucose and FA metabolism. Altogether these data suggest that oleate or linolenate may act on different subpopulations of neurons (or astrocytes) thus highlighting the fact that FAs may have different effect in regard of the area in which they act. It is also interesting that expression of gene such as GPR41 can be also modified by linolenate infusion. Indeed it has been recently evidenced that short-chain fatty acids and ketones directly regulate sympathetic nervous system via GPR41 at the level of sympathetic ganglion (Kimura et al., 2011). Thus changes in hypothalamic GRP41 gene expression may have an impact during starvation, a situation in which ketone bodies production is increased. thereby control body energy expenditure in maintaining metabolic homeostasis.

In the second part of our work we demonstrated a differential role of PUFA vs saturated FA (SFA) regarding induction of insulin resistance and ceramides production in hypothalamus by using triglyceride emulsion infusion, in order to mimic a more "physiological approach". 
Indeed $24 \mathrm{~h}$ of lard oil infusion in carotid which had no effect on plasma TG or FA concentrations (data not shown) induced a glucose intolerance suggesting a deregulation of insulin sensitivity and or secretion. This deleterious effect of lard oil in nervous control of glucose homeostasis was associated with an increased in DAG and ceramides content in hypothalamus. An important role for ceramides has emerged from research on the pathogenesis of metabolic diseases associated with obesity, such as diabetes (Holland \& Summers, 2008). Indeed, ceramides appear to be particularly deleterious components of the lipid milieu that accrues in obesity, and levels of ceramides are often elevated in skeletal muscle, liver, and/or serum of obese humans and rodents (Adams et al., 2004; Clement et al., 2002). DAG and ceramides are known to activate kinase such as PKC, which phosphorylate insulin receptor substrate and Akt leading to an inhibition of the insulin signaling (Mullen et al., 2009; Newton et al., 2009). A recent study also evidenced that sphingolipids such as ceramide might be key components of the signaling networks that link lipid-induced inflammatory pathways to the antagonism of insulin action that contributes to diabetes (Holland et al., 2011). We also recently demonstrated that the atypical protein kinase $\mathrm{C}, \mathrm{PKC} \Theta$, is expressed in discrete neuronal populations of the ARC and the dorsal medial hypothalamic nucleus (Benoit et al., 2009). CNS exposure to saturated palmitic acid via direct infusion or by oral gavage increased the localization of PKC $\Theta$ to hypothalamic cell membranes in association impaired hypothalamic insulin and leptin signaling (Benoit et al., 2009). This finding was specific for palmitic acid, as the monounsaturated FA, OA, neither increased membrane localization of PKC $\Theta$ nor reduced insulin signaling. Finally, ARC-specific knockdown of PKC $\Theta$ attenuated diet-induced obesity and improved hypothalamic insulin signaling (Benoit et al., 2009). These results suggest that many of the deleterious effects of high fat diets, specifically those enriched with palmitic acid, are CNS mediated via PKC $\Theta$ activation, resulting in reduced insulin activity. Therefore, our data suggest that ceramide accumulation in the hypothalamus following icv infusion of saturated fatty acid could contribute to the installation of an insulin resistant state by altering nervous output and consequently nervous control of insulin secretion and action.

Further studies are needed to clearly identify molecular mechanism relaying ceramides production. However there is now several experiments highlighting some of these mechanisms in FA sensitive neurons as described below.

\subsection{Molecular mechanisms involved in neuronal FA sensing}

In FA sensitive neurons, exposure to long chain FA can alter the activity of a wide variety of ion channels including $\mathrm{Cl}^{-}, \mathrm{GABA}_{\mathrm{A}}$ (Tewari et al., 2000), potassium, $\mathrm{K}^{+} \mathrm{Ca}^{2+}$ (Honen et al., 2003) or calcium channels (Oishi et al., 1990). Additionally, FA inhibit the $\mathrm{Na}^{+}-\mathrm{K}^{+}$ATPase pump (Oishi et al., 1990). For example, OA activates ARC POMC neurons by inhibiting ATP-sensitive $\mathrm{K}^{+}\left(\mathrm{K}_{\mathrm{ATP}}\right)$ channel activity (Jo et al., 2009) and the effect of OA on HGP is abolished by icv administration of a $\mathrm{K}_{\mathrm{ATP}}$ channel inhibitor (Jo et al., 2009). However, $\mathrm{K}_{\mathrm{ATP}}$ channels are ubiquitously expressed on neurons throughout the brain, not only in FA sensing neurons, making the mechanism and site of such in vivo manipulations difficult to discern (Dunn-Meynell et al., 1998). Using in vivo and in vitro electrophysiological approaches, OA sensitive-neurons have been characterized using whole cell patch clamp 
records in ARC slices from 14 to 21 day old rats (Wang et al., 2006). Of these $13 \%$ were excited by OA and 30\% were inhibited by OA (Oomura et al., 1975). The excitatory effects of OA appeared to be due to closure of chloride channels leading to membrane depolarization and increased action potential frequency (Migrenne et al., 2006). On the other hand, inhibitory effect of OA may involve the $\mathrm{K}_{\mathrm{ATP}}$ channels since this inhibition was reversed by the $\mathrm{K}_{\mathrm{ATP}}$ channel blocker tolbutamide (Migrenne et al., 2006). Using fura-2 $\mathrm{Ca}^{2+}$ imaging in dissociated neurons from the ventromedial hypothalamic nucleus (VMN) neurons, we found that OA excited up to $43 \%$ and inhibited up to $29 \%$ of all VMN neurons independently of glucose concentrations (Le Foll et al., 2009). However, in these neurons, inhibition of the $\mathrm{K}_{\mathrm{ATP}}$ channel mediated FA sensing in only a small percentage of FA sensing neurons. Importantly, although a relatively large percentage of hypothalamic neurons are FA sensors, a select population that also sense glucose are highly dependent upon ambient glucose concentrations for the resultant effect of FA on the activity of these neurons (Le Foll et al., 2009). Such data suggest that the responses of hypothalamic FA sensitive neurons are dependent upon the metabolic state of the animal and thus might be expected to respond differently during fasting (when FA levels rise and glucose levels fall) vs. the overfed state when glucose levels rise while free FA levels remain relatively unchanged (Le Foll et al., 2009). However, it must be pointed out that FA are naturally complexed to serum albumin in the blood and the concentration of circulating free FA is less than $1 \%$ of total FA levels. All the studies investigating FA sensing in the hypothalamus either use non-complexed FA or cyclodextrin-complexed FA in vitro or in vivo. The concentration of free FA in cyclodextrin-complexed FA preparation is unknown. Whether or not the FA concentration used mimics FA levels in physiological states needs to be determined.

\subsection{Metabolic-dependent FA sensing effects}

The effects of FA on activity of some neurons are dependent upon intracellular metabolism of FA. Enzymes involved in FA metabolism such as FA synthase (FAS), CPT1 and acetylCoA carboxylase (ACC) are expressed in some hypothalamic neurons as well as in glial cells (reviewed in (Blouet \& Schwartz; Le Foll et al., 2009). Malonyl-CoA may be an important sensor of energy levels in the hypothalamus. It is derived from either glucose or FA metabolism via the glycolysis or $\beta$-oxidation, respectively. The steady-state level of malonylCoA is determined by its rate of synthesis catalysed by ACC relative to its rate of turnover catalysed by FAS. The synthesis of malonyl-CoA is the first committed step of FA synthesis and ACC is the major site of regulation in that process. Thus, when the supply of glucose is increased, malonyl CoA levels increase in keeping with a decreased need for FA oxidation. This increase in both malonyl CoA and acyl CoA levels is associated with reduced food intake. Central administration of C75, an inhibitor of FAS, also increases malonyl-CoA concentration in the hypothalamus, suppresses food intake and leads to profound weight loss (Proulx \& Seeley, 2005). It has been proposed that centrally, C75 and cerulenin (another inhibitor of FAS) alter the expression profiles of feeding-related neuropeptides, often inhibiting the expression of orexigenic peptides such as neuropeptide Y (Proulx et al., 2008). Whether through centrally mediated or peripheral mechanisms, C75 also increases energy expenditure, which contributes to weight loss (Clegg et al., 2002; Tu et al., 2005). In vitro and in vivo studies demonstrate that at least part of C75's effects are mediated by the 
modulation of AMP-activated kinase, a known energy-sensing kinase (Ronnett et al., 2005). Indeed, icv administration of 5-aminoimidazole-4-carboxamide ribonucleoside (AICAR), a 5'-AMP kinase activator, rapidly lowers hypothalamic malonyl-CoA concentration and increases food intake ( $\mathrm{Tu}$ et al., 2005). These effects correlate closely with the phosphorylation-induced inactivation of ACC, an established target of AMP kinase. Collectively, these data suggest a role for FA metabolism in the perception and regulation of energy balance. However, it must be also pointed out that C75 and AICAR may also have nonspecific or even opposite effects. For example, a major effect of C75 is to activate CPT-1 rather than lead to its inhibition in vitro (Aja et al., 2008). Finally the route of administration and the type of FA used are also critical. For example, bolus intracerebroventricular injections of OA, but not palmitic acid, reduce food intake and body weight, possibly mediated through POMC/MC4R signaling (Schwinkendorf et al., 2010). Again, such bolus icv injections could cause non-specific effects related to inflammation of ependymocytes and tanycytes. Also because so much of FA metabolism takes place in astrocytes, such manipulations done in vivo and in slice preparations are likely to alter FA metabolism that takes place in astrocytes which could then indirectly alter neuronal FA sensing (Escartin et al., 2007).

\subsection{Non metabolic-dependent neuronal FA sensing}

While intracellular FA metabolism may be responsible for altering neuronal activity in some FA sensitive neurons such as ARC POMC neurons (Jo et al., 2009) it accounts for a relatively small percent of the effects of OA on dissociated VMN neurons (Le Foll et al., 2009). In those neurons, inhibition of CPT1, reactive oxygen species formation, long-chain acyl CoA synthetase and $\mathrm{K}_{\mathrm{ATP}}$ channel activity or activation of uncoupling protein 2 (UCP2) accounts for no more than $20 \%$ of the excitatory or approximately $40 \%$ of the inhibitory effects of OA (Le Foll et al., 2009). On the other hand, pharmacological inhibition of FAT/CD36, a FA transporter/receptor that can alter cell function independently of intracellular FA metabolism reduced the excitatory and inhibitory effects of OA by up to $45 \%$ (Le Foll et al., 2009). Thus, in almost half of VMN FA sensing neurons, CD36 may act primarily as receptor, rather than a transporter, for long chain FA as it does on taste cells on the tongue where it activates store-operated calcium channels to alter membrane potential and release of serotonin (Gaillard et al., 2008). These effects all occur in the presence of nanomolar concentrations of $\mathrm{OA}$, whereas micromolar concentrations are generally required to effect similar changes in neuronal activity in brain slice preparations (Jo et al., 2009; Migrenne et al., 2011; Wang et al., 2006). Thus, in the absence of astrocytes, OA can directly affect VMN neuronal activity through both metabolic and non-metabolic pathways. Alternatively, FA might act as signaling molecules by covalent attachment to proteins (N-terminal acylation) to alter the function of membrane and intracellular signaling molecules. For example, palmitoylation facilitates the targeting and plasma membrane binding of proteins which otherwise would remain in the cytosolic compartment (Resh, 1999). Some membrane proteins (TGF $\alpha$, synaptosomal associated protein of $25 \mathrm{KDa}$ (required for exocytosis) and plasma membrane receptors (seven transmembrane receptors such as $\alpha_{2 a^{-}}$and $\beta_{2^{-}}$ adrenoceptors) are typically palmitoylated on one or several cysteine residues located adjacent to or just within the transmembrane domain (Resh, 1999) Such mechanisms might also modulate neuronal FA sensing. 


\subsection{Which neurotransmitters or neuropeptides?}

The ultimate consequence of the activation or inactivation of a neuron is the release of neurotransmitters and neuropeptides. Since FA decrease food intake, they might be expected to alter activity neurons specifically involved in the regulation of feeding. In fact, OA activates catabolic POMC neurons directly, apparently via B-oxidation and inactivation of the $\mathrm{K}_{\mathrm{ATP}}$ channel in hypothalamic slice preparations (Jo et al., 2009). In vivo, Obici et al. (Obici et al., 2003) reported that icv administration of OA markedly inhibits glucose production and food intake, accompanied by a decrease in the hypothalamic expression of the anabolic peptide, neuropeptide $Y$. This decrease in the expression of such a critical anabolic peptide might contribute to the reduced food intake associated with direct central administration of OA. On the other hand, an n-3 FA enriched diet increases food intake in anorexic tumor-bearing rats, in association with reduced tumor appearance, tumor growth and onset of anorexia (Ramos et al., 2005). In these treated rats, neuropeptide Y immunoreactivity increased $38 \%$ in ARC and $50 \%$ in paraventricular nucleus, whereas amelanocyte stimulating hormone (a catabolic peptide cleavage product of POMC) decreased $64 \%$ in the ARC and $29 \%$ in the paraventricular nucleus (Ramos et al., 2005). Finally, in the hippocampus, docosahexaenoic acid $(22: 6(n-3)$ increased the spontaneous release of acetylcholine (Aid et al., 2005).

\subsection{Pathological implications of excess FA}

Besides physiological regulation of energy balance by hypothalamic neuronal FA sensing, impaired regulation of such sensing might contribute to the development of metabolic diseases such as obesity and type 2 diabetes in predisposed subjects exposed to a chronic lipid overload (Luquet \& Magnan, 2009; Migrenne et al., 2011). Excessive brain lipid levels may indeed alter control of glucose and lipid homeostasis through changes of autonomic nervous system activity. Increasing brain FA levels reduces sympathetic activity and increases GIIS in rats (Clement et al., 2002; Obici et al., 2003) a condition which would exacerbate the development of type 2 diabetes mellitus. Also, a lipid overload due to highfat diet intake alters both hypothalamic monoamine turnover (Levin et al., 1983) and peripheral sympathetic activity in rats (Young \& Walgren, 1994). In humans, overweight is often associated with an altered sympathetic tone (Peterson et al., 1988) suggesting a relationship between lipids and autonomic control centers in brain.

\section{Conclusion}

In conclusion, there is now increasing evidence that specialized neurons within hypothalamus and other areas such as the brainstem or hippocampus can detect changes in plasma FA levels by having FA directly or indirectly alter the of FA sensitive neurons involved in the regulation of energy and glucose homeostasis. Central FA effects on insulin secretion and action are related to their chain length or degree of saturation. Such effects are also mediated through differential changes in gene expression.

The neuronal networks of these FA sensitive neurons that sense and respond to FA are likely very complex given the fact that FA can either inhibit or excite specific neurons. In addition, many of these neurons also utilize glucose as a signaling molecule and there is often an inverse responsiveness of such "metabolic sensing" neurons to FA vs. glucose. 
Thus, these neurons are ideally suited to respond differentially under a variety of metabolic conditions such as fasting, feeding, hypo- or hyperglycemia. However, while it is clear that specific neurons can respond to changes in ambient FA levels, many questions remain. We still do not know for certain how FA are transported into the brain, astrocytes or neurons and whether those FA that are transported are derived from circulating free FA or triglycerides. Since most studies suggest that rising FA levels reduce food intake, then we must explain why plasma FA levels are most elevated during fasting when the drive to seek and ingest food should be at its strongest. Another major issue relates to the interaction between astrocytes and neurons with regard to the metabolism and signaling of FA. Also, we still know little about the basic mechanisms utilized by neurons to sense FA, where such FA sensitive neurons reside throughout the brain and what neurotransmitters and peptides they release when responding to FA.

Finally, it has been postulated that diabetes may be a disorder of the brain (Elmquist \& Marcus, 2003). If so, dysfunction of these FA sensitive neurons could be, at least in part, one of the early mechanisms underlying impairment of neural control of energy and glucose homeostasis and the development of obesity and type 2 diabetes in predisposed subjects. A better understanding of this central nutrient sensing, including both FA and glucose, could provide clues for the identification of new therapeutic targets for the prevention and treatment of both diabetes and obesity.

\section{Acknowledgements}

This work was partially supported by an award from European Foundation for Study of Diabetes (EFSD)/GSK 2007 (Stéphanie Migrenne).

\section{References}

Adams JM, 2nd; Pratipanawatr T; Berria R; Wang E; DeFronzo RA; Sullards MC \& Mandarino LJ. (2004). Ceramide content is increased in skeletal muscle from obese insulin-resistant humans. Diabetes, Vol. 53, No. 1, pp 25-31, 0012-1797 (Print) 00121797 (Linking)

Aid S; Vancassel S; Linard A; Lavialle M \& Guesnet P. (2005). Dietary docosahexaenoic acid [22: $6(n-3)]$ as a phospholipid or a triglyceride enhances the potassium chlorideevoked release of acetylcholine in rat hippocampus. J Nutr, Vol. 135, No. 5, pp 10081013,

Aja S; Landree LE; Kleman AM; Medghalchi SM; Vadlamudi A; McFadden JM; Aplasca A; Hyun J; Plummer E; Daniels K; Kemm M; Townsend CA; Thupari JN; Kuhajda FP; Moran TH \& Ronnett GV. (2008). Pharmacological stimulation of brain carnitine palmitoyl-transferase-1 decreases food intake and body weight. Am J Physiol Regul Integr Comp Physiol, Vol. 294, No. 2, pp R352-361, 0363-6119 (Print) 0363-6119 (Linking)

Benoit SC; Kemp CJ; Elias CF; Abplanalp W; Herman JP; Migrenne S; Lefevre AL; Cruciani-Guglielmacci C; Magnan C; Yu F; Niswender K; Irani BG; Holland WL \& Clegg DJ. (2009). Palmitic acid mediates hypothalamic insulin resistance by 
altering PKC-theta subcellular localization in rodents. J Clin Invest, Vol. 119, No. 9, pp 2577-2589,

Blouet C \& Schwartz GJ. (2010). Hypothalamic nutrient sensing in the control of energy homeostasis. Behav Brain Res, Vol. 209, No. 1, pp 1-12,

Clegg DJ; Air EL; Woods SC \& Seeley RJ. (2002). Eating elicited by orexin-a, but not melanin-concentrating hormone, is opioid mediated. Endocrinology, Vol. 143, No. 8, pp 2995-3000,

Clement L; Cruciani-Guglielmacci C; Magnan C; Vincent M; Douared L; Orosco M; Assimacopoulos-Jeannet F; Penicaud L \& Ktorza A. (2002). Intracerebroventricular infusion of a triglyceride emulsion leads to both altered insulin secretion and hepatic glucose production in rats. Pflugers Arch, Vol. 445, No. 3, pp 375-380,

Cruciani-Guglielmacci C; Hervalet A; Douared L; Sanders NM; Levin BE; Ktorza A \& Magnan C. (2004). Beta oxidation in the brain is required for the effects of nonesterified fatty acids on glucose-induced insulin secretion in rats. Diabetologia, Vol. 47, No. 11, pp 2032-2038,

Dowell P; Hu Z \& Lane MD. (2005). Monitoring energy balance: metabolites of fatty acid synthesis as hypothalamic sensors. Annu Rev Biochem, Vol. 74, No. pp 515-534,

Dunn-Meynell AA; Rawson NE \& Levin BE. (1998). Distribution and phenotype of neurons containing the ATP-sensitive K+ channel in rat brain. Brain Res, Vol. 814, No. 1-2, pp 41-54, 0006-8993 (Print) 0006-8993 (Linking)

Edmond J. (2001). Essential polyunsaturated fatty acids and the barrier to the brain: the components of a model for transport. J Mol Neurosci, Vol. 16, No. 2-3, pp 181-193; discussion 215-121,

Elmquist JK \& Marcus JN. (2003). Rethinking the central causes of diabetes. Nat Med, Vol. 9, No. 6, pp 645-647,

Escalante-Alcalde D; Hernandez L; Le Stunff H; Maeda R; Lee HS; Jr Gang C; Sciorra VA; Daar I; Spiegel S; Morris AJ \& Stewart CL. (2003). The lipid phosphatase LPP3 regulates extra-embryonic vasculogenesis and axis patterning. Development, Vol. 130, No. 19, pp 4623-4637, 0950-1991 (Print) 0950-1991 (Linking)

Escartin C; Boyer F; Bemelmans AP; Hantraye P \& Brouillet E. (2007). IGF-1 exacerbates the neurotoxicity of the mitochondrial inhibitor 3NP in rats. Neurosci Lett, Vol. 425, No. 3, pp 167-172, 0304-3940 (Print) 0304-3940 (Linking)

Escartin C; Pierre K; Colin A; Brouillet E; Delzescaux T; Guillermier M; Dhenain M; Deglon N; Hantraye P; Pellerin L \& Bonvento G. (2007). Activation of astrocytes by CNTF induces metabolic plasticity and increases resistance to metabolic insults. J Neurosci, Vol. 27, No. 27, pp 7094-7104, 1529-2401 (Electronic) 0270-6474 (Linking)

Gaillard D; Laugerette F; Darcel N; El-Yassimi A; Passilly-Degrace P; Hichami A; Khan NA; Montmayeur JP \& Besnard P. (2008). The gustatory pathway is involved in CD36mediated orosensory perception of long-chain fatty acids in the mouse. FASEB J, Vol. 22, No. 5, pp 1458-1468, 1530-6860 (Electronic) 0892-6638 (Linking) 
Gilbert M; Magnan C; Turban S; Andre J \& Guerre-Millo M. (2003). Leptin receptor-deficient obese Zucker rats reduce their food intake in response to a systemic supply of calories from glucose. Diabetes, Vol. 52, No. 2, pp 277-282,

Gribble FM; Proks P; Corkey BE \& Ashcroft FM. (1998). Mechanism of cloned ATP-sensitive potassium channel activation by oleoyl-CoA. J Biol Chem, Vol. 273, No. 41, pp 26383-26387, 0021-9258 (Print) 0021-9258 (Linking)

Holland WL; Bikman BT; Wang LP; Yuguang G; Sargent KM; Bulchand S; Knotts TA; Shui G; Clegg DJ; Wenk MR; Pagliassotti MJ; Scherer PE \& Summers SA. (2011). Lipidinduced insulin resistance mediated by the proinflammatory receptor TLR4 requires saturated fatty acid-induced ceramide biosynthesis in mice. J Clin Invest, Vol. 121, No. 5, pp 1858-1870, 1558-8238 (Electronic) 0021-9738 (Linking)

Holland WL \& Summers SA. (2008). Sphingolipids, insulin resistance, and metabolic disease: new insights from in vivo manipulation of sphingolipid metabolism. Endocr Rev, Vol. 29, No. 4, pp 381-402, 0163-769X (Print) 0163-769X (Linking)

Honen BN; Saint DA \& Laver DR. (2003). Suppression of calcium sparks in rat ventricular myocytes and direct inhibition of sheep cardiac RyR channels by EPA, DHA and oleic acid. J Membr Biol, Vol. 196, No. 2, pp 95-103,

Jo YH; Su Y; Gutierrez-Juarez R \& Chua S, Jr. (2009). Oleic acid directly regulates POMC neuron excitability in the hypothalamus. J Neurophysiol, Vol. 101, No. 5, pp 23052316, 0022-3077 (Print) 0022-3077 (Linking)

Kimura I; Inoue D; Maeda T; Hara T; Ichimura A; Miyauchi S; Kobayashi M; Hirasawa A \& Tsujimoto G. (2011). Short-chain fatty acids and ketones directly regulate sympathetic nervous system via G protein-coupled receptor 41 (GPR41). Proc Natl Acad Sci U S A, Vol. 108, No. 19, pp 8030-8035, 1091-6490 (Electronic) 0027-8424 (Linking)

Lam TK; Schwartz GJ \& Rossetti L. (2005). Hypothalamic sensing of fatty acids. Nat Neurosci, Vol. 8, No. 5, pp 579-584,

Le Foll C; Irani BG; Magnan C; Dunn-Meynell AA \& Levin BE. (2009). Characteristics and mechanisms of hypothalamic neuronal fatty acid sensing. Am J Physiol Regul Integr Comp Physiol, Vol. 297, No. 3, pp R655-664,

Le Stunff H; Galve-Roperh I; Peterson C; Milstien S \& Spiegel S. (2002). Sphingosine-1phosphate phosphohydrolase in regulation of sphingolipid metabolism and apoptosis. J Cell Biol, Vol. 158, No. 6, pp 1039-1049, 0021-9525 (Print) 0021-9525 (Linking)

Levin BE; Triscari J \& Sullivan AC. (1983). Altered sympathetic activity during development of diet-induced obesity in rat. Am J Physiol, Vol. 244, No. 3, pp R347-355,

Luquet S \& Magnan C. (2009). The central nervous system at the core of the regulation of energy homeostasis. Front Biosci (Schol Ed), Vol. 1, No. pp 448-465,

Magnan C; Collins S; Berthault MF; Kassis N; Vincent M; Gilbert M; Penicaud L; Ktorza A \& Assimacopoulos-Jeannet F. (1999). Lipid infusion lowers sympathetic nervous activity and leads to increased beta-cell responsiveness to glucose. J Clin Invest, Vol. 103, No. 3, pp 413-419, 
Magnan C; Cruciani C; Clement L; Adnot P; Vincent M; Kergoat M; Girard A; Elghozi JL; Velho G; Beressi N; Bresson JL \& Ktorza A. (2001). Glucose-induced insulin hypersecretion in lipid-infused healthy subjects is associated with a decrease in plasma norepinephrine concentration and urinary excretion. J Clin Endocrinol Metab, Vol. 86, No. 10, pp 4901-4907,

Migrenne S; Cruciani-Guglielmacci C; Kang L; Wang R; Rouch C; Lefevre AL; Ktorza A; Routh V; Levin B \& Magnan C. (2006). Fatty acid signaling in the hypothalamus and the neural control of insulin secretion. Diabetes, Vol. 55 S2, No. pp S139-S144,

Migrenne S; Le Foll C; Levin BE \& Magnan C. (2011). Brain lipid sensing and nervous control of energy balance. Diabetes Metab, Vol. 37, No. 2, pp 83-88, 1878-1780 (Electronic) 1262-3636 (Linking)

Migrenne S; Marsollier N; Cruciani-Guglielmacci C \& Magnan C. (2006). Importance of the gut-brain axis in the control of glucose homeostasis. Curr Opin Pharmacol, Vol. 6, No. 6, pp 592-597,

Mullen KL; Pritchard J; Ritchie I; Snook LA; Chabowski A; Bonen A; Wright D \& Dyck DJ. (2009). Adiponectin resistance precedes the accumulation of skeletal muscle lipids and insulin resistance in high-fat-fed rats. Am J Physiol Regul Integr Comp Physiol, Vol. 296, No. 2, pp R243-251, 0363-6119 (Print) 0363-6119 (Linking)

Newton RU; Taaffe DR; Spry N; Gardiner RA; Levin G; Wall B; Joseph D; Chambers SK \& Galvao DA. (2009). A phase III clinical trial of exercise modalities on treatment side-effects in men receiving therapy for prostate cancer. BMC Cancer, Vol. 9, No. pp 210, 1471-2407 (Electronic) 1471-2407 (Linking)

Obici S; Feng Z; Arduini A; Conti R \& Rossetti L. (2003). Inhibition of hypothalamic carnitine palmitoyltransferase-1 decreases food intake and glucose production. Nat Med, Vol. 9, No. 6, pp 756-761,

Obici S; Feng Z; Morgan K; Stein D; Karkanias G \& Rossetti L. (2002). Central administration of oleic acid inhibits glucose production and food intake. Diabetes, Vol. 51, No. 2, pp 271-275,

Oishi K; Zheng B \& Kuo JF. (1990). Inhibition of Na,K-ATPase and sodium pump by protein kinase $\mathrm{C}$ regulators sphingosine, lysophosphatidylcholine, and oleic acid. J Biol Chem, Vol. 265, No. 1, pp 70-75,

Oomura Y; Nakamura T; Sugimori M \& Yamada Y. (1975). Effect of free fatty acid on the rat lateral hypothalamic neurons. Physiol Behav, Vol. 14, No. 04, pp 483-486,

Penicaud L; Leloup C; Lorsignol A; Alquier T \& Guillod E. (2002). Brain glucose sensing mechanism and glucose homeostasis. Curr Opin Clin Nutr Metab Care, Vol. 5, No. 5, pp 539-543,

Peterson HR; Rothschild M; Weinberg CR; Fell RD; McLeish KR \& Pfeifer MA. (1988). Body fat and the activity of the autonomic nervous system. N Engl J Med, Vol. 318, No. 17, pp 1077-1083,

Proulx K; Cota D; Woods SC \& Seeley RJ. (2008). Fatty acid synthase inhibitors modulate energy balance via mammalian target of rapamycin complex 1 signaling in the central nervous system. Diabetes, Vol. 57, No. 12, pp 3231-3238,

Proulx K \& Seeley RJ. (2005). The regulation of energy balance by the central nervous system. Psychiatr Clin North Am, Vol. 28, No. 1, pp 25-38, vii, 
Ramos EJ; Romanova IV; Suzuki S; Chen C; Ugrumov MV; Sato T; Goncalves CG \& Meguid MM. (2005). Effects of omega-3 fatty acids on orexigenic and anorexigenic modulators at the onset of anorexia. Brain Res, Vol. 1046, No. 1-2, pp 157-164,

Randle PJ; Priestman DA; Mistry S \& Halsall A. (1994). Mechanisms modifying glucose oxidation in diabetes mellitus. Diabetologia, Vol. 37 Suppl 2, No. pp S155-161, 0012186X (Print) 0012-186X (Linking)

Rapoport SI; Chang MC \& Spector AA. (2001). Delivery and turnover of plasma-derived essential PUFAs in mammalian brain. J Lipid Res, Vol. 42, No. 5, pp 678-685,

Resh MD. (1999). Fatty acylation of proteins: new insights into membrane targeting of myristoylated and palmitoylated proteins. Biochim Biophys Acta, Vol. 1451, No. 1, pp 1-16,

Ronnett GV; Kim EK; Landree LE \& Tu Y. (2005). Fatty acid metabolism as a target for obesity treatment. Physiol Behav, Vol. 85, No. 1, pp 25-35,

Ross RA; Rossetti L; Lam TK \& Schwartz GJ. (2010). Differential effects of hypothalamic long-chain fatty acid infusions on suppression of hepatic glucose production. Am J Physiol Endocrinol Metab, Vol. 299, No. 4, pp E633-639, 1522-1555 (Electronic) 01931849 (Linking)

Ruge T; Hodson L; Cheeseman J; Dennis AL; Fielding BA; Humphreys SM; Frayn KN \& Karpe F. (2009). Fasted to fed trafficking of Fatty acids in human adipose tissue reveals a novel regulatory step for enhanced fat storage. J Clin Endocrinol Metab, Vol. 94, No. 5, pp 1781-1788, 1945-7197 (Electronic) 0021-972X (Linking)

Schwinkendorf DR; Tsatsos NG; Gosnell BA \& Mashek DG. (2010). Effects of central administration of distinct fatty acids on hypothalamic neuropeptide expression and energy metabolism. Int J Obes (Lond), Vol. No. pp 1476-5497 (Electronic) 0307-0565 (Linking)

Smith QR \& Nagura H. (2001). Fatty acid uptake and incorporation in brain: studies with the perfusion model. J Mol Neurosci, Vol. 16, No. 2-3, pp 167-172; discussion 215121 ,

Tewari KP; Malinowska DH; Sherry AM \& Cuppoletti J. (2000). PKA and arachidonic acid activation of human recombinant $\mathrm{ClC}-2$ chloride channels. Am J Physiol Cell Physiol, Vol. 279, No. 1, pp C40-50,

Tu Y; Thupari JN; Kim EK; Pinn ML; Moran TH; Ronnett GV \& Kuhajda FP. (2005). C75 alters central and peripheral gene expression to reduce food intake and increase energy expenditure. Endocrinology, Vol. 146, No. 1, pp 486-493,

Wang R; Cruciani-Guglielmacci C; Migrenne S; Magnan C; Cotero VE \& Routh VH. (2006). Effects of oleic acid on distinct populations of neurons in the hypothalamic arcuate nucleus are dependent on extracellular glucose levels. J Neurophysiol, Vol. 95, No. 3, pp 1491-1498,

Watkins PA; Hamilton JA; Leaf A; Spector AA; Moore SA; Anderson RE; Moser HW; Noetzel MJ \& Katz R. (2001). Brain uptake and utilization of fatty acids: applications to peroxisomal biogenesis diseases. J Mol Neurosci, Vol. 16, No. 2-3, pp 87-92; discussion 151-157, 
Young JB \& Walgren MC. (1994). Differential effects of dietary fats on sympathetic nervous system activity in the rat. Metabolism, Vol. 43, No. 1, pp 51-60, 


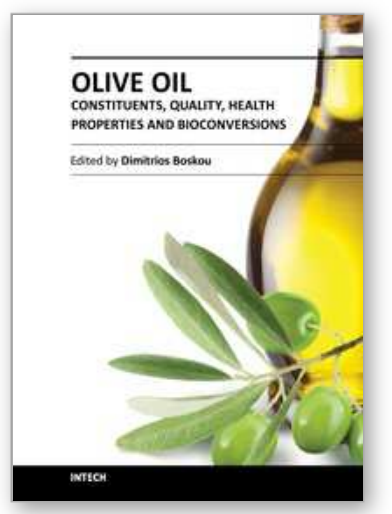

\section{Olive Oil - Constituents, Quality, Health Properties and Bioconversions}

Edited by Dr. Dimitrios Boskou

ISBN 978-953-307-921-9

Hard cover, 510 pages

Publisher InTech

Published online 01, February, 2012

Published in print edition February, 2012

The health-promoting effects attributed to olive oil, and the development of the olive oil industry have intensified the quest for new information, stimulating wide areas of research. This book is a source of recently accumulated information. It covers a broad range of topics from chemistry, technology, and quality assessment, to bioavailability and function of important molecules, recovery of bioactive compounds, preparation of olive oil-based functional products, and identification of novel pharmacological targets for the prevention and treatment of certain diseases.

\section{How to reference}

In order to correctly reference this scholarly work, feel free to copy and paste the following:

Christophe Magnan, Hervé Le Stunff and Stéphanie Migrenne (2012). Differential Effect of Fatty Acids in Nervous Control of Energy Balance, Olive Oil - Constituents, Quality, Health Properties and Bioconversions, Dr. Dimitrios Boskou (Ed.), ISBN: 978-953-307-921-9, InTech, Available from:

http://www.intechopen.com/books/olive-oil-constituents-quality-health-properties-andbioconversions/differential-effect-of-fatty-acids-in-nervous-control-of-energy-balance

\section{INTECH}

open science | open minds

\section{InTech Europe}

University Campus STeP Ri Slavka Krautzeka 83/A 51000 Rijeka, Croatia Phone: +385 (51) 770447 Fax: +385 (51) 686166 www.intechopen.com

\section{InTech China}

Unit 405, Office Block, Hotel Equatorial Shanghai No.65, Yan An Road (West), Shanghai, 200040, China 中国上海市延安西路65号上海国际贵都大饭店办公楼405单元 Phone: +86-21-62489820

Fax: +86-21-62489821 
(C) 2012 The Author(s). Licensee IntechOpen. This is an open access article distributed under the terms of the Creative Commons Attribution 3.0 License, which permits unrestricted use, distribution, and reproduction in any medium, provided the original work is properly cited. 